\title{
Measurement of carrier lifetime and linewidth enhancement factor for 1.5- mu m ridge- waveguide laser amplifier
}

Storkfelt, Niels; Mikkelsen, B.; Olesen, D. S.; Yamaguchi, M.; Stubkjær, Kristian

Published in:

I E E E Photonics Technology Letters

Link to article, DOI:

$10.1109 / 68.87936$

Publication date:

1991

Document Version

Publisher's PDF, also known as Version of record

Link back to DTU Orbit

Citation (APA):

Storkfelt, N., Mikkelsen, B., Olesen, D. S., Yamaguchi, M., \& Stubkjær, K. (1991). Measurement of carrier lifetime and linewidth enhancement factor for 1.5- mu $\mathrm{m}$ ridge-waveguide laser amplifier. I E E E Photonics Technology Letters, 3(7), 632-634. https://doi.org/10.1109/68.87936

\section{General rights}

Copyright and moral rights for the publications made accessible in the public portal are retained by the authors and/or other copyright owners and it is a condition of accessing publications that users recognise and abide by the legal requirements associated with these rights.

- Users may download and print one copy of any publication from the public portal for the purpose of private study or research.

- You may not further distribute the material or use it for any profit-making activity or commercial gain

- You may freely distribute the URL identifying the publication in the public portal 


\title{
Measurement of Carrier Lifetime and Linewidth Enhancement Factor for 1.5- $\mu \mathrm{m}$ Ridge-Waveguide Laser Amplifier
}

\author{
N. Storkfelt, B. Mikkelsen, D. S. Olesen, M. Yamaguchi, and K. E. Stubkjaer
}

\begin{abstract}
Semiconductor optical amplifiers are used for investigation of the effective carrier lifetime and the linewidth enhancement factor. Contrary to semiconductor lasers semiconductor optical amplifiers allow measurement at high levels of injected carrier density. The carrier lifetime and the linewidth enhancement factor are measured with a simple dynamic selfheterodyne method. Carrier lifetimes of $750 \mathrm{ps}$ at the threshold current for the SOA without antireflection coating and $200 \mathrm{ps}$ at high injection have been found. The linewidth enhancement factor is measured to be between 4 and 17 which fits with a simple empirical expression.
\end{abstract}

\section{INTRODUCTION}

$\mathrm{T}$ HE EFFECTIVE carrier lifetime $\tau_{e}$ and the linewidth enhancement factor $\alpha$ are two important key parameters for semiconductor lasers and semiconductor optical amplifiers (SOA) as reported in many publications, e.g., [1]-[3]. Several measurement techniques have been proposed [4]-[6]. Here we present a method for measuring the $\alpha$ factor and the carrier lifetime by use of a SOA. The measurements are based on a small-signal modulation of the SOA and has the advantage of being simple and since it is a dynamic measurement technique thermal effects are reduced. Furthermore, the use of traveling-wave amplifiers allows measurement of the two parameters under high carrier injection contrary to measurements on semiconductor lasers for which the carrier density is clamped at low levels.

\section{$\alpha$ FACTOR}

The measurements of the $\alpha$ factor are based on a smallsignal modulation of the carrier density of the amplifier obtained by modulation of the bias current. Since the gain and the refractive index is dependent on the carrier density, a modulation of the carrier density will generate amplitude-

Manuscript received February 6, 1991; revised April 25, 1991

N. Storkfelt, B. Mikkelsen, and K. E. Stubkjaer are with the Center for Broadband Telecommunications, Electromagnetics Institute, Technical University of Denmark, DK-2800 Lyngby, Denmark.

D. S. Olesen was with the Center for Broadband Telecommunication, Electromagnetics Institute, Technical University of Denmark, DK-2800 Lyngby, Denmark. He is now with NKT., DK-2605 Brondby, Denmark.

M. Yamaguchi is with the Center for Broadband Telecommunications, Electromagnetics Institute, Technical University of Denmark, DK-2800 Lyngby, Denmark, on leave from NEC Corporation, Kanagawa 213, Japan.

IEEE Log Number 9101426. modulation (AM) and frequency-modulation (FM) of a given amplified signal. As will be shown below, the ratio between the FM and AM indices determines the $\alpha$-factor.

From a small-signal analysis, which is based on a traveling-wave model similar to the one proposed by Adams et al. [7] but with a more detailed recombination model [8], the modulation amplitude $\delta N$ of the carrier density for a given amplitude $\delta I$ of the modulation current is given by [3]

$$
\delta N=\frac{\delta I}{e V} \frac{\tau_{e}}{\sqrt{1+\left(\omega_{m} \tau_{e}\right)^{2}}}
$$

where $e$ is the electron charge, $V$ is the volume of the active region, $\omega_{m}$ is the modulation angular frequency, and $\tau_{e}$ is the effective carrier lifetime which will be accurately defined in the following section.

As mentioned above the carrier density modulation generates AM and FM. From the small-signal analysis it can be shown that the AM-index $m$ is given by: $m=\frac{1}{2} L \Gamma \frac{d g}{d N} \cdot \delta N$ and the FM-index $\beta$ by: $\beta=\frac{\omega}{c} \mathrm{~L} \Gamma \frac{d n}{d N} \cdot \delta N . \Gamma$ is the optical confinement factor, $c$ is the light velocity in vacuum, and $L$ is the length of the active region. The $\alpha$ factor is then directly calculated from the ratio of the measured indexes [6]:

$$
\alpha=-2 k \frac{d n / d N}{d g / d N}=-2 \frac{\omega}{c} \frac{d n / d N}{d g / d N}=-\frac{\beta}{m} .
$$

When the effective carrier lifetime is known it is also possible to derive $d g / d N$ and $d n / d N$ from the measured AM- and FM-indexes.

The setup for measuring the $\alpha$ factor is identical with that in Fig. 1 without laser no. 2. An external cavity laser is used as a signal source and a part of the signal is amplitude- and frequency-modulated by the amplifier. The modulated output signal from the amplifier is then detected with a selfheterodyne technique which uses the frequency-shifted signal from the acoustooptic modulator as reference signal. In order to reduce the influence of the amplified spontaneous emission on the AM index the amplified signal passes through a grating filter. A lightwave analyzer displays the selfheterodyned beat spectrum from which the AM- and FM-indexes are deter- 


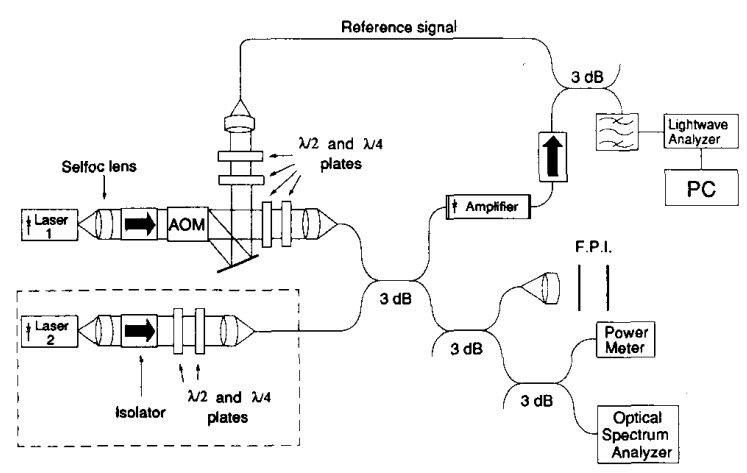

Fig. 1. Setup for measuring the linewidth enhancement factor and effective carrier lifetime. The lasers are external cavity lasers and the AOM designates an acoustooptic modulator.

mined. The major advantages of this measurement technique are that the $\alpha$ factor can be determined from one single measurement, that only one signal source has to be controlled and that no calibration is needed.

\section{CARrier Lifetime}

From a small-signal analysis, the effective carrier lifetime $\tau_{e}$ can in the most general case be given by

$$
\tau_{e}^{-1}=\tau_{s}^{-1}+v_{g} \cdot \frac{g L+1}{g L} \cdot \frac{d g(\bar{N}, \omega)}{d N} \cdot S_{\text {out }}
$$

where $\tau_{s}$ is the differential carrier lifetime equal to the inverse of the derivative of the spontaneous recombination rate to the carrier density, $\bar{N}$ is the average carrier density, $g(\bar{N}, \omega)$ is the gain as described below in (4), $\omega$ is the angular frequency of the signal, $v_{g}$ is the steady-state group velocity, and $S_{\text {out }}$ is the output photon density. It should be noted that the differential carrier lifetime is two to three times lower than the static carrier lifetime which is used to determine the static carrier concentration.

As seen from (1), the effective carrier lifetime indicates how fast the carrier density can be modulated. Obviously, $\tau_{e}$ can be determined by measuring the AM index versus the modulation frequency of the injection current. However, the parasitic capacitances of the amplifier and the bias circuit has to be taken into account. To overcome the influence of this, carrier modulation can also be accomplished by beating two closely spaced optical input signals [2]. In this case the amplitude $\delta N$ depends on beat frequency and effective carrier lifetime in the same way as shown in (1) with the modulation frequency being replaced by the beat frequency. The setup for measuring $\tau_{e}$ with optically generated modulation of the carrier density is in principle identical to that for $\alpha$ factor measurements except that a second signal source is necessary. The experimental configuration is shown in Fig. 1 .

\section{RESULTS}

The amplifier under investigation is a $500 \mu \mathrm{m}$ long $1.5 \mu \mathrm{m}$ ridge-waveguide angled facet laser amplifier with a cross-section of the active region of $3.3 \cdot 0.15 \mu \mathrm{m}^{2}$. The active region is tilted $7^{\circ}$ compared to the facet normal and the residual reflectivity is $5 \cdot 10^{-5}$ [9]. It should be emphasized that a small reflectivity is essential for precise measurement since a residual Fabry-Perot structure in the gain will especially influence the AM index. In the following we will normalize the bias current to the threshold current $I_{\text {th }}$ of a similar device with uncoated straight facets $\left(I_{\text {th }}=40 \mathrm{~mA}\right)$. The amplifier is biased up till five times $I_{\text {th }}$ where the unsaturated gain is $25 \mathrm{~dB}$ and the signal output power is approximately $+1 \mathrm{dBm}$. For comparison, the saturation output power is $+7 \mathrm{dBm}$.

The measured $\alpha$ factors are given in Fig. 2 as a function of bias current with wavelength as a parameter. At a normalized bias current of 2.5 and $25 \mathrm{~nm}$ below the peak gain wavelength $\left(\lambda_{p}=1525 \mathrm{~nm}\right)$ an $\alpha$ factor of approximately 4 is measured. At high injection current $\left(I / I_{\text {th }} \approx 5\right)$ and $18 \mathrm{~nm}$ above the gain peak wavelength $\left(\lambda_{p}=1512 \mathrm{~nm}\right) \alpha$ factors of up to 17 are found.

The measured dependency of the $\alpha$ factor with current and wavelength is well interpreted by assuming $d n / d N$ constant with bias current and using the following expression for the gain [8]:

$$
g(N, \lambda)=g_{N}\left(N-N_{0}\right)-\gamma_{\lambda}\left(\lambda-\lambda_{p}(N)\right)^{2}
$$

where $N$ is the carrier density found from the rate equation normally used for SOA's, [7], $g_{N}$ is the gain constant, $N_{0}$ the carrier density at transparency, and $\gamma_{\lambda}$ accounts for the wavelength dependency. $\lambda_{p}(N)$ is the wavelength at the gain peak which is assumed to vary linearly with carrier density. As explained by (4) the increase in $\alpha$ factor with bias current is due to the decrease of the peak wavelength $\left(\lambda_{p}\right)$ with an increase in carrier density [5]. It is also seen that the $\alpha$ factor increases with wavelength and above the gain peak wavelength the increase is very fast as reported previously [10], [11]. This increase is mainly due to the decrease in $d g / d N$ but also due to a small increase in $d n / d N$. The measured $\alpha$ factors at low bias levels are in accordance with previously published results for semiconductor lasers [6], [11] and the values measured at high carrier injection agree well with values presented by Kikuchi [12].

The effective carrier lifetime is measured using both electrical and optical generated modulation of the carriers, and the results are shown in Fig. 3 as triangles and circles, respectively. The effective carrier lifetime decreases with increasing bias current and values as low as 200 ps have been measured. It is also noted that there is good agreement between the values measured with the two different measurement methods. The effective carrier lifetime is approximately $650 \mathrm{ps}$ at a normalized bias current of 1 . At an output power lower than $+1 \mathrm{dBm}$ the second term in (3) contributes less than $5 \%$ to the total $\tau_{e}$ and the solid curve is therefore calculated from the spontaneous recombination rate $R(N)=$ $a_{1} N+b_{1} N^{2}+c_{1} N^{3}$ with $a_{1}=2.0 \cdot 10^{8} \mathrm{~s}^{-1}, b_{1}=1.5 \cdot$ $10^{-16} \mathrm{~m}^{3} \mathrm{~s}^{-1}$ and $c_{1}=1.5 \cdot 10^{-40} \mathrm{~m}^{6} \mathrm{~s}^{-1}$. The dashed curve is calculated using the previously published value of $c_{1}=7.5 \times 10^{-41} \mathrm{~m}^{6} \mathrm{~s}^{-1}$ [13]. At high bias currents the best fit is obtained with the large Auger constant while at low bias conditions the smaller value of the Auger constant also fits the measured data. The predicted value of the Auger recom- 


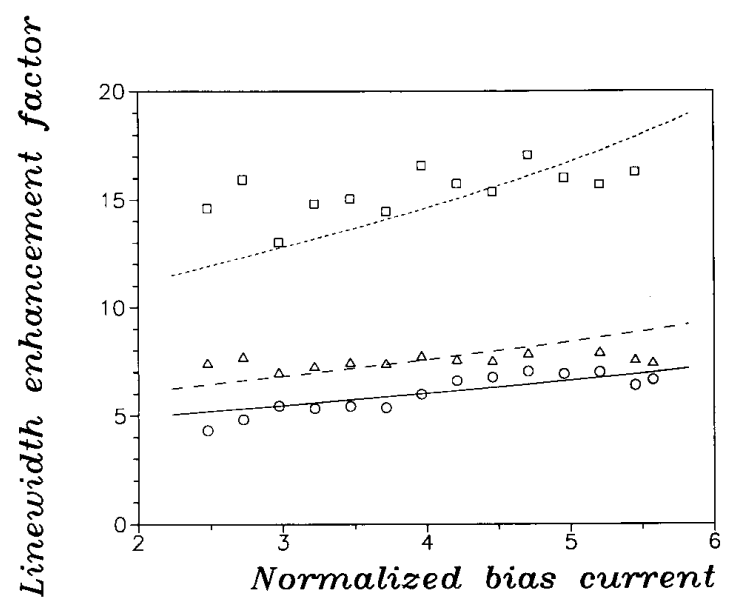

Fig. 2. Linewidth enhancement factor versus normalized bias current for wavelengths $\lambda=1500 \mathrm{~nm}(O), 1510 \mathrm{~nm}(\triangle)$ and $1530 \mathrm{~nm}(\square)$. Solid and dashed curves are calculated assuming $d n / d N$ to be constant with bias current and dependent on wavelength. $d n / d N$ values of $2.21 \times 10^{-26} \mathrm{~m}^{3}$, $2.52 \times 10^{-26} \mathrm{~m}^{3}$, and $3.03 \times 10^{-26} \mathrm{~m}^{3}$ were used at the three wavelengths, respectively. $d g / d N$ is obtained from (4) with $g_{N}=2.9 \times 10^{-20}$ $\mathrm{m}^{2}, N_{0}=0.90 \times 10^{24} \mathrm{~m}^{-3}$ and $\gamma_{\lambda}=4.6 \times 10^{18} \mathrm{~m}^{-3}$

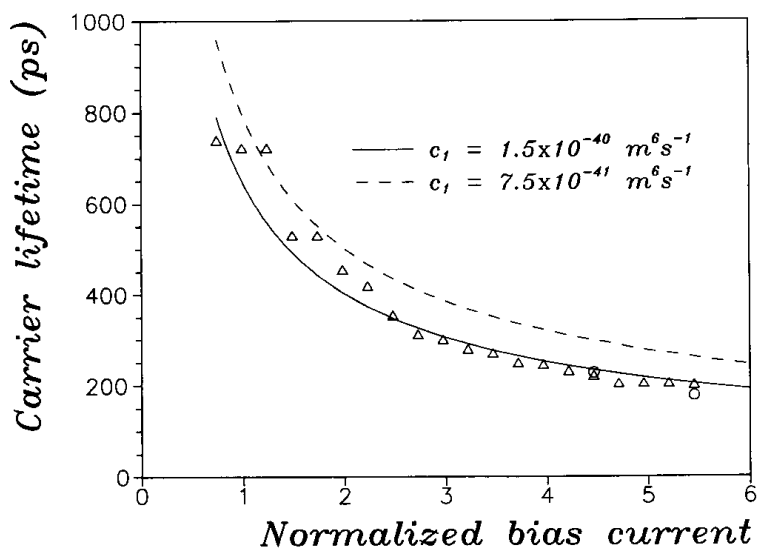

Fig. 3. Effective carrier lifetime versus normalized bias current. The measured results shown are obtained with current modulation $(\triangle)$ and with optical modulation (O). The solid and the dashed curve represents the calculated differential carrier lifetime using our fitted Auger recombination constant and previously reported Auger constant. The other recombination constants are given in the text.

bination constant $c_{1}$ is two to three times higher than the usually reported values, e.g., [13], but is lower than the $3.2 \times 10^{-40} \mathrm{~m}^{6} \mathrm{~s}^{-1}$ reported in [14]. Naturally our predicted recombination coefficients are sensitive to measurement uncertainties which in our case are estimated to $10 \%$. Measurement uncertainties of $\pm 10 \%$ can change the Auger constant by $\pm 0.4 \times 10^{-40} \mathrm{~m}^{6} \mathrm{~s}^{-1}$ while the other recombination parameters would be almost constant. To clarify the discrepancies in reported Auger recombination constants further studies will have to be conducted.

\section{Conclusion}

The effective carrier lifetime $\tau_{e}$ has been measured as function of bias current using two measurement methods.
The measured $\tau_{e}$ is in agreement with a simple model for the recombination rate and values between 200 and 750 ps have been found. The AM- and FM-indexes have been measured with a self-heterodyne technique and used to determine the $\alpha$ factors. The measured $\alpha$ factors at a normalized bias of 2.5 and at a wavelength $25 \mathrm{~nm}$ below the gain peak are approximately 4 and values as high as 17 has been found at a normalized bias current of 5 and at a wavelength $18 \mathrm{~nm}$ above the gain peak. For low injection current, the measured $\alpha$ factors at the gain peak agree well with previously reported values for semiconductor lasers [10]. In conclusion, characterization of laser amplifiers is a convenient way to determine material parameters.

\section{ACKNOWLEDGMENT}

We thank Dr. A. J. Collar and Dr. G. D. Henshall of STC-Technology, Harlow, England for supplying the laser amplifiers.

\section{REFERENCES}

[1] C. H. Henry, "Theory of the linewidth of semiconductor lasers," IEEE J. Quantum Electron., vol. QE-18, pp. 259-264, Feb. 1982

[2] G. P. Agrawal, "Four-wave mixing and phase conjugation in semiconductor laser media," Opt. Lett., vol. 12, pp. 260-262, Apr. 1987.

[3] G. Grosskopf, R. Ludwig, R. Schnabel, and H. G. Weber, "Characteristics of semiconductor laser optical amplifier as phase modulator," Electron. Lett., vol. 25, pp. 1188-1189, Aug. 1989.

[4] I. D. Henning and J. V. Collins, "Measurements of the semiconductor laser linewidth broadening factor," Electron. Lett., vol. 19, pp. 927-929, Oct. 1983.

[5] L. D. Westbrook, "Dispersion of linewidth-broadening factor in 1.5 $\mu \mathrm{m}$ laser diodes," Electron. Lett., vol. 21, pp. 1018-1019, Oct. 1985.

[6] C. Harder, K. Vahala, and A. Yariv, "Measurement of the linewidth enhancement factor $\alpha$ of semiconductor lasers," Appl. Phys. Lett., vol. 42, pp. 328-330, Feb. 1983.

[7] M. J. Adams, J. V. Collins, and I. D. Henning, "Analysis of semiconductor laser optical amplifiers," IEE Proc. Pt. J, vol. 132, pp. 58-63, Feb. 1985.

[8] J. Wang, H. Olesen, and K. E. Stubkjaer, "Recombination, gain, and bandwidth characteristics of $1.3-\mu \mathrm{m}$ semiconductor laser amplifiers," J. Lightwave Technol., vol. LT-5, pp. 184-189, Jan. 1987.

[9] Z. Wang, B. Mikkelsen, K. E. Stubkjaer, D. S. Olesen, T. Durhuus, P. B. Hansen, A. J. Collar, and G. D. Henshall, "Low reflectivity angled facet laser amplifiers," in IEEE Lasers Electroopt. Soc. Conf., Orlando, FL, pp. 309-310, Oct. 1989, paper OE13.1

[10] M. Osinski and J. Buus, "Linewidth broadening factor in semiconductor lasers-An overview," IEEE J. Quantum Electron., vol. QE-23, pp. 9-29, Jan. 1987.

[11] L. D. Westbrook, "Measurements of $d g / d N$ and $d n / d N$ and their dependence on photon energy in $\lambda=1.5 \mu \mathrm{m}$ InGaAsP laser diodes," IEE Proc. Pt. J, vol. 133, pp. 135-142, Apr. 1986

[12] K. Kikuchi, T. Itatani, C. E. Zah, and T. P. Lee, "Carrier lifetime and linewidth enhancement factor measurements from cross-modulation characteristics in semiconductor optical amplifiers," in 12th IEEE Internat. Semiconductor Laser Conf., Davos, Switzerland, pp. 130-131, Sept. 1990, paper I-3.

[13] E. Wintner and E. P. Ippen, "Nonlinear carrier dynamics in $\mathrm{Ga}_{x} \mathrm{In}_{1-x} \mathrm{As}_{y} \mathrm{P}_{1-y}$ compounds," Appl. Phys. Lett., vol. 44, pp. $999-1001$, May 1984 .

[14] S. Hausser, G. Fuchs, A. Hangleiter, K. Streubel, and W. T. Tsang, "Auger recombination in bulk and quantum well InGaAs," Appl. Phys. Lett., vol. 56, pp. 913-915, Mar. 1990. 